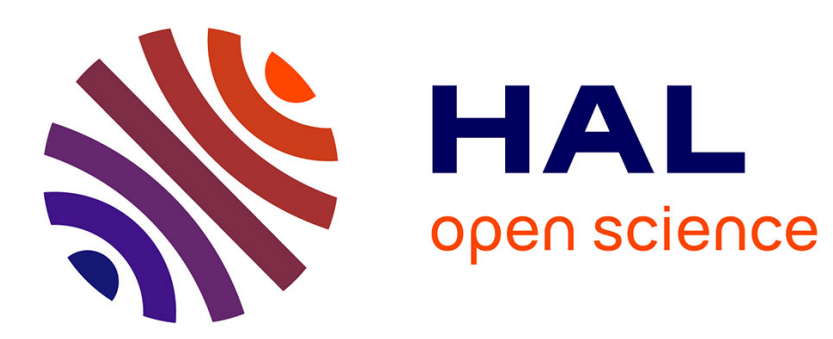

\title{
Fundamental characteristics of thickness vibrations of langasite plates for baw resonators
}

\author{
V. Bezdelkin, E. Antonova
}

\section{To cite this version:}

V. Bezdelkin, E. Antonova. Fundamental characteristics of thickness vibrations of langasite plates for baw resonators. Journal de Physique IV Proceedings, 1994, 04 (C2), pp.C2-139-C2-156. 10.1051/jp4:1994217 . jpa-00252485

\section{HAL Id: jpa-00252485 https://hal.science/jpa-00252485}

Submitted on 1 Jan 1994

HAL is a multi-disciplinary open access archive for the deposit and dissemination of scientific research documents, whether they are published or not. The documents may come from teaching and research institutions in France or abroad, or from public or private research centers.
L'archive ouverte pluridisciplinaire HAL, est destinée au dépôt et à la diffusion de documents scientifiques de niveau recherche, publiés ou non, émanant des établissements d'enseignement et de recherche français ou étrangers, des laboratoires publics ou privés. 


\title{
Fundamental characteristics of thickness vibrations of langasite plates for baw resonators
}

\author{
V.V. BEZDELKIN and E.E. ANTONOVA
}

Scientific Research Institute "Fonon", 105023 Moscow, Krasnobogatyrskaya 44, Russia

\begin{abstract}
Based on theoretical and experimental investigations further possibility of $\mathrm{La}_{3} \mathrm{Ga}_{5} \mathrm{SiO}_{14}$ - langasite (LGS) application for BAW resonators is described. Anisotropy of frequency coefficients $N_{f}$, temperature- frequency coefficients (TCF), electromechanical coupling coefficients ( $\mathrm{k}_{\mathrm{s}}$ ) for these modes of vibration of langasite has been investigated.
\end{abstract}

1. Introduction

For the first time langasite crystals have been grown up and investigated in Russia at the begin of eighties during the search of new promising crystals for 1 asers [1-5]. Later a high acoustic quality factor, a piezoelectric effect stronger than that of quartz and the orientation existence with zero temperature coefficient of frequency (TCF) for BAW have been discovered in this material. Resonators fabricated of these crystals had rather attractive parameters $[6,7]$. Moreover, langasite does not have phase transitions during heating from the room temperature up to the melting temperaturas which gives the possibility to apply it in products operating under severe conditions. This has servedas basis for further investigation of langasite crystal properties and their application in piezoelectric engineering.

2. Main physical properties of crystals under investization

Characteristics of thickness vibrations of singlemand doublerotated cuts of langasite have been investigated ( $N_{f}$, TCF, $k_{g}$ ) for the $A, B, C$-modes of vibration aimed at finding orientations with minimum temperature coefficient of frequency (TCF) and high electromechanical coupling factor. 
Elastic stifinesess $C_{i k}^{E}\left(10^{10} \mathrm{~N} / \mathrm{m}^{2}\right)$

\begin{tabular}{|cccccccc|}
\hline$c_{11}$ & $c_{12}$ & $c_{13}$ & $c_{14}$ & $c_{33}$ & $c_{44}$ & $c_{55}$ & \\
\hline 19.09 & 10.63 & 10.42 & 1.52 & 26.19 & 5.24 & 4.32 & {$[2]$} \\
19.02 & 10.63 & 9.19 & 1.47 & 26.21 & 5.382 & 4.20 & {$[4]$} \\
13.89 & 10.46 & 9.68 & 1.43 & 26.22 & 5.39 & 4.22 & {$[5]$} \\
19.01 & 10.30 & 9.83 & 1.57 & 26.83 & 5.331 & 4.35 & {$[11]$} \\
\hline
\end{tabular}

Table 2

Elastic compliances $s_{i \mathrm{k}}^{E}\left(10^{-13} \mathrm{~m}^{2} / \mathrm{N}\right)$

\begin{tabular}{|lrrrrrrr|}
\hline$s_{11}$ & $s_{12}$ & $s_{13}$ & $s_{14}$ & $s_{33}$ & $s_{44}$ & $s_{56}$ & \\
\hline 27.64 & -40.32 & -18.51 & -35.9 & 55.91 & 210 & 255.9 & {$[2]$} \\
87.52 & -40.21 & -18.82 & -37.9 & 53.15 & 215.85 & 255.4 & {$[4]$} \\
87.7 & -42.7 & -16.6 & -34.6 & 50.4 & 203 & - & {$[5]$} \\
\hline
\end{tabular}

Tahle 3

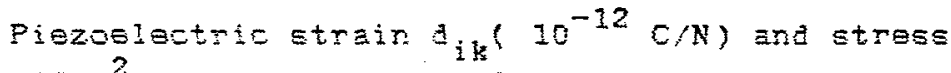
$e_{i k}\left(\mathrm{C}_{\mathrm{m}}^{2}\right)$ constants and electromechanical couping factors $\mathrm{s}$

\begin{tabular}{|c|c|c|c|c|c|c|}
\hline$a_{11}$ & $a_{14}$ & $\theta_{11}$ & $\theta_{14}$ & $k_{12}$ & $\mathrm{k}_{25}$ & $k_{t}$ \\
\hline-5.16 & 5.36 & -0.45 & 0.077 & 0.15 & 0.134 & $0.08[2]$ \\
\hline
\end{tabular}


Table 4

\begin{tabular}{|c|c|c|c|c|c|c|c|}
\hline & $\begin{array}{l}g^{\circ} 5 \pi \\
10^{10}\end{array}$ & $\begin{array}{l}\text { ulus } \\
\mathrm{m}^{2}, \text { a }\end{array}$ & $\begin{array}{ll}i & \left(10^{\circ}\right. \\
d & P O i\end{array}$ & $\begin{array}{l}\left.N / m^{2}\right), \\
o n{ }^{*} s\end{array}$ & $\begin{array}{l}\text { shear } \\
\text { atios }\end{array}$ & $\begin{array}{l}\text { modulus } \\
\sigma_{i k}\end{array}$ & \\
\hline$G_{11}$ & $G_{33}$ & $E_{11}$ & $E_{33}$ & $\alpha_{12}$ & $\sigma_{13}$ & $\sigma_{31}$ & \\
\hline 4.21 & 4.45 & 11.13 & 18.81 & 0.459 & 0.35 & 0.215 & [2] \\
\hline
\end{tabular}

Table 5

Dielectric permittivity constants $e_{i j}^{T}, s_{i j}^{S}$,specific resistance $\rho_{\theta}\left(10^{3} \mathrm{ohm} \cdot \mathrm{cm}\right)$ and dielectric $\operatorname{losses} \operatorname{tg} \delta\left(10^{-3}\right)$.

\begin{tabular}{|cccccccc|}
\hline $\mathrm{T}$ & $\mathrm{S}$ & $\mathrm{T}$ & $\mathrm{s}$ & $\rho_{11}$ & $\rho_{33}$ & $\operatorname{tg} \delta$ & \\
\hline 18.99 & 18.87 & 49.32 & 49.32 & 1.5 & 0.8 & - & {$[2]$} \\
18.86 & - & 49.10 & - & - & - & 0.11 & {$[5]$} \\
\hline
\end{tabular}

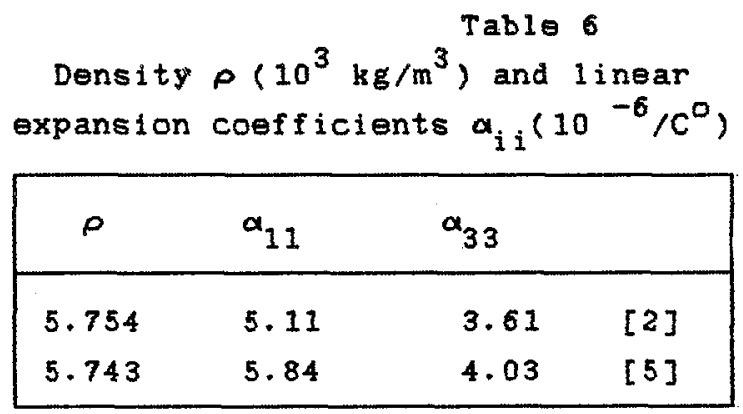


Table 7

Thermal expansion coefficlents $T C_{1 k}\left(10^{-6} /{ }^{\circ} \mathrm{C}\right)$

\begin{tabular}{|cccccccc|}
\hline $\mathrm{TC}_{11}$ & $\mathrm{TC}_{12}$ & $\mathrm{TC}_{13}$ & $\mathrm{TC}_{14}$ & $\mathrm{TC}_{33}$ & $\mathrm{TC}_{44}$ & $\mathrm{TC}_{66}$ & \\
\hline-47 & -100 & -130 & -370 & -94 & -30 & +36 & {$[4]$} \\
-58.7 & -218 & -101 & -154 & -135 & -79.7 & 139 & {$[5]$} \\
-52.7 & -107.4 & +0.7 & -176 & -105 & -57.6 & +12 & {$[11]$} \\
\hline
\end{tabular}

Table 8

Thermal expansion coefficients $\mathrm{TS}_{1 \mathrm{k}}\left(10^{-6},{ }^{\circ} \mathrm{C}\right)$

\begin{tabular}{|llllllll|}
\hline TS $_{11}$ & TS $_{12}$ & TS $_{13}$ & TS $_{14}$ & TS $_{33}$ & TS $_{44}$ & TS $_{66}$ & \\
\hline-96.6 & -337 & 165 & -250 & 151 & 43.4 & - & {$[5]$} \\
\hline
\end{tabular}

Table 9

Thermal expansion coefficients $T \theta_{1 k}\left(10^{-6},{ }^{\circ} \mathrm{C}\right)$, $\mathrm{Td}_{i k}\left(10^{-6},{ }^{\circ} \mathrm{C}\right)+e_{j k}\left(10^{-6},{ }^{\circ} \mathrm{C}\right)$

\begin{tabular}{|ccccccc|}
\hline$T \theta_{11}$ & $\mathrm{T \theta}_{33}$ & $\mathrm{Td}$ & $\mathrm{Td}$ & $\mathrm{T} \varepsilon_{11}$ & $\mathrm{~T} \varepsilon_{33}$ & \\
\hline-2400 & -5000 & -2680 & -3320 & 447 & 618 & {$[5]$} \\
& & & & 153 & -760 & {$[4]$} \\
\hline
\end{tabular}

Table 10

Thermal expansion coeficients $T 2 C_{1 k}\left(10^{-9},{ }^{\circ} \mathrm{C}\right)$

\begin{tabular}{|lllllllll|}
\hline $\mathrm{T2C}_{11}$ & $\mathrm{T2C}_{12}$ & $\mathrm{~T}_{13} \mathrm{~T}_{14}$ & $\mathrm{~T}_{33}$ & $\mathrm{~T}_{44}$ & $\mathrm{~T}_{26}$ & \\
\hline-113 & +1085 & -117 & +452 & +65 & +102 & -1564 & {$[5]$} \\
-55.4 & +48.1 & +1294 & -10.4 & -62.8 & -133 & -178 & {$[10]$} \\
\hline
\end{tabular}


Table 11

Phase velosity of elastic waves $v\left(10^{3} \mathrm{~m} / \mathrm{c}\right)$ and temperature dependence elastic waves TV $\left(10^{-6},{ }^{\circ} \mathrm{C}\right), \operatorname{T} 2 \mathrm{v}\left(10^{-9},{ }^{\circ} \mathrm{C}\right)$ of langasite crystals

\begin{tabular}{|c|c|c|c|c|c|c|}
\hline \multirow{2}{*}{$\begin{array}{l}\text { Direction } \\
\text { of propa- } \\
\text { gation }\end{array}$} & \multirow{2}{*}{$\begin{array}{l}\text { Waye } \\
\text { type }\end{array}$} & \multicolumn{3}{|c|}{$v$} & \multirow{2}{*}{$\begin{array}{l}\text { TV } \\
{[10]}\end{array}$} & \multirow{2}{*}{$\frac{\mathrm{T} 2 \mathrm{~V}}{[10]}$} \\
\hline & & [3] & [5] & [10] & & \\
\hline$x$ & XLL. & 5.784 & 5.748 & 5.746 & -24.9 & -24.7 \\
\hline$y$ & XFS & 3.344 & - & 3.305 & -53.2 & -39.1 \\
\hline$x$ & YS & 2.344 & 2.380 & 2.394 & +49.8 & -42.0 \\
\hline$Y$ & YQL & 5.792 & 5.754 & 5.756 & -31.0 & -42.0 \\
\hline$Y$ & YQS & 2.971 & 3.015 & 3.003 & -18.8 & -57.5 \\
\hline$Y$ & YS & 2.767 & 2.745 & 2.750 & +6.6 & -89.0 \\
\hline 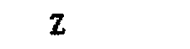 & $\mathbf{Z L}$ & 6.753 & 6.750 & 6.826 & -50.0 & -29.2 \\
\hline$z$ & 2S & 3.021 & 3.061 & 3.043 & -26.5 & -04.9 \\
\hline$[011]$ & $+45 Y Z Q L$ & 5.998 & - & 5.900 & -40.1 & -377.0 \\
\hline$[011]$ & +45YZQS & 3,141 & - & 3.281 & $-52 \cdot 2$ & -87.0 \\
\hline
\end{tabular}

Table 12

Acoustic characteristics: velocity $v_{1 t}\left(10^{3} \mathrm{~m} / \mathrm{s}\right)$ and attenuation $(\mathrm{dB} / \mathrm{cm})$ of elastic waves in aifferentcrystals at the frequency of $830 \mathrm{MHz}\left(20^{\circ} \mathrm{C}\right)$

\begin{tabular}{|ccccccc|}
\hline Crystal & \multicolumn{2}{c}{ Pure longitudinal } & \multicolumn{2}{c|}{ Pure transversal } \\
\hline$[3.11]$ & $\begin{array}{c}\text { along } \\
\text { velocity }\end{array}$ & attenuation & velocity & attenuation \\
\hline $\mathrm{SiO}_{2}$ & 5.751 & 2.38 & 3.914 & 3.4 & {$[3]$} \\
$\mathrm{La}_{3} \mathrm{Ga}_{5} \mathrm{SiO}_{14}$ & 5.784 & 0.45 & 2.767 & 1.6 & {$[2]$} \\
$\mathrm{Ca}_{3} \mathrm{Ga}_{5} \mathrm{Ge}_{4} \mathrm{O}_{14}$ & 5.85 & 0.6 & 2.757 & 3.9 & {$[3]$} \\
$\mathrm{Sr}_{2} \mathrm{Ga}_{2} \mathrm{Ge}_{4} \mathrm{O}_{14}$ & 5.576 & 0.8 & 2.791 & 2.8 & {$[3]$} \\
$\mathrm{Y}_{3} \mathrm{Al}_{5} \mathrm{O}_{12}$ & 8.62 & 0.3 & 4.95 & 1.1 & {$[3]$} \\
\hline
\end{tabular}


Frequency constants of different crystals

Mode of vibration $\mathrm{SiO}_{2} \mathrm{La}_{3} \mathrm{Ga}_{5} \mathrm{SiO} \mathrm{I}_{14} \mathrm{Ca}_{3} \mathrm{Ga} \mathrm{a}_{2} \mathrm{Ge}_{4} \mathrm{O}_{14} \mathrm{Sr}_{2} \mathrm{Ga}_{2} \mathrm{Ge}_{4} \mathrm{O}_{14}$ [2] [3] [3]

Thickness-extensional mode

$x$-cut plate

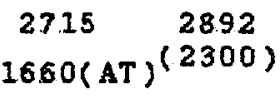

Thickness-shear mode

2550(BT) 1382

Piezorlectric constants $d_{i k}\left(10^{-12} \mathrm{c} / \mathrm{N}\right), \theta_{i k}\left(c / \mathrm{m}^{2}\right), k_{\delta}(\%)$ of differend crystals

\begin{tabular}{|cccccccccc|}
\hline Crystal[3,11] & $d_{11}$ & $d_{14}$ & $\theta_{11}$ & $e_{14}$ & $k_{12}$ & $k_{t}$ & $k_{26}$ & $\varepsilon_{11}$ & $\varepsilon_{33}$ \\
\hline $\mathrm{SiO}_{2}$ & 2.3 & -0.68 & -1.62 & -0.41 & 10 & 9 & 14 & 4.52 & 4.64 \\
$\mathrm{La}_{3} \mathrm{Ga}_{5} \mathrm{SiO}_{14}$ & -6.16 & 5.36 & -0.45 & 0.077 & 26 & 8 & 13.4 & 18.99 & 49.32 \\
$\mathrm{Ca}_{3} \mathrm{Ga}_{2} \mathrm{Ga}_{4} \mathrm{O}_{14}$ & -5.38 & 2.58 & -0.344 & 0.0014 & 14.5 & 10.2 & 12.5 & 15.5 & 24.22 \\
$\mathrm{Sr}_{2} \mathrm{Ga}_{2} \mathrm{Ge}_{4} \mathrm{O}_{14}$ & -9.41 & 0.96 & -0.567 & 0.055 & 26.64 & 13 & 28 & 13.8 & 18.21 \\
\hline
\end{tabular}


The present paper utilizes the results of crystal properties measurement published in $[1-5,10,11]$, several of them are represented in tables $1-14$.

The analysis of main langasite crystal properties snows that in accordance with Mason's classification, this crystal belongs to piezoelectrics possessing a moderately strong piezoelectric effect. Piezoelectric moduli of langasite are 1.5 times. greater than those of quartz, but considerably less than those of lithium tantalate.

A high acoustic quality factor is characteristic for langasite. In comparison with quartz langasite has nigher acoustic quality factor. Hypersound attenuation of a shear wave in langasite at a frequency of $830 \mathrm{MHz}$ along the $Y$-axis is 3 times 1 less and that of longitudinal wave, is 5 times less than those of quartz and is comparable with the wave attenuation in YAG.

An important langasite property is the poseibility of the substitution of the structure elemente La, Ga, Si by other elements and in obtaining based thereon of new compositions and solid-state solutions with the calcium-gallium-germanate structure, for example:

$$
\begin{aligned}
& \mathrm{La}_{3} \mathrm{Ga}_{5} \mathrm{SiO}_{14} ; \mathrm{Na}_{3} \mathrm{Ga}_{5} \mathrm{SiO}_{14} ; \mathrm{La}_{3} \mathrm{Ga} \mathrm{a}_{5} \mathrm{Na}_{0,5^{\circ}} \mathrm{O}_{14}: \mathrm{La}_{3} \mathrm{Ga} \mathrm{a}_{5,5} \mathrm{Ta}_{0,5} \mathrm{O}_{14} \text {; } \\
& \mathrm{La}_{3} \mathrm{Ga}_{5} \mathrm{GeO}_{14} ; \mathrm{Sr}_{3} \mathrm{Ga}_{2} \mathrm{Ge}_{4} \mathrm{O}_{14} \text {. }
\end{aligned}
$$

Several physical characteristics of the above-mentioned langasite compositions in accordance with the data published in [1-3], are given in tables 12-14, from which, it follows that the compositions of this type can possess a diverse physical characteristic spectrum, for example, to have $k_{\sigma}$ near to that of LBO. Their application in piezoelectric engineering can enable development of resonators with necessary parameters based on the "basic" LGS-structure.

The analysis of acoustical and electromecnanical of properties of langasite crystal shows, that langasite can be effectively used for resonators operating in longitudinal, flexural, face snear and thickness- shear modes.

\section{Theoretical investigations of thickness - shear vibrations in}

\section{langasite plates}

Evaluation nas been made by using a computer taking into account crystal properties measurement data obtained in $[2,4]$.

second -order temperature constants have not been used in this paper due to necessity of further investigations.

As the basis for the calculation method, one-dimensional model 
of thicuness vibrations of an infinite piezoelectric plate developed by Tiersten and Yamada $[8,9]$ has been used.

The electrical impedance of a piezoelectric plate vibrating in thickness -shear mode can be written as:

$$
z=\frac{1}{j C_{0} \omega}\left[1-\sum_{i=1}^{3} k(i) 2 \frac{t_{g \theta^{(i)}}}{\theta^{(i)}}\right]
$$

where $\theta^{(i)}=\frac{\omega t}{2 v(i)}=\frac{\pi t}{v^{(i)}}$.

$C_{0}{ }^{-}$is the static capacitance of the plate;

$t$ - is the plate thickness:

$i^{(i)}$, (i) $v_{-}$is the lectromechanical coupling factor and the phase velocity of the ith mode of vibration;

$\omega, f$ - are angular and linear frequencies. respectively;

$j$ - is an imaginary unit.

The expression for antiresonance frequeneies is obtained from the the condition $z \rightarrow \infty\left(t g \theta^{(i)} \rightarrow \infty\right)$.

$$
f_{a}^{(i)}=\frac{n \theta^{(i)}}{2 t} \text {. }
$$

where $n$ - is the overtone order $(n=1,3,5 \ldots)$ and the condition $z=0$ determines resonance frequencies $F_{r}^{(i)}$, which are the roots of the following equation :

$$
1-\sum k^{(i) 2} \frac{t_{g}(i)}{\theta^{(i)}}=0
$$

Phase velocity and the electromechanical coupling coefficient of the ith mode are calculated as:

$$
\begin{aligned}
& u^{(i)}=\sqrt{\frac{e^{(i)}}{\rho}}, \\
& k^{(i)}=\frac{e^{(i)}}{a e^{(i)}},
\end{aligned}
$$

where $\rho$ - is density.

$\varepsilon, e^{(i)}, c^{(i)}$, are effective values of dielectric permeability, plezoelectric constant and stiffness modulus for BAw, propagating in the direction $\vec{n}=\left(n_{1}, n_{2}, n_{3}\right)$ with polarization vector $\vec{p}=\left(p_{1}, p_{2}, p_{3}\right)$. 
The values of $e^{(i)}$ and $p$ are eigenvalues and eigenvectors respectively of Green-Kristoffel $G_{i f}$, the components of which are determined for the piezoelectric medium as:

$$
G_{i k}=c_{i j k 1} n_{j} n_{1}+\frac{\gamma_{i} \gamma_{k}}{\varepsilon}
$$

where $\quad \gamma_{i}=e_{k i j} n_{j} n_{k}$.

$$
=e_{j k}^{5} n_{j} n_{k}, \quad i, j, k, 1=1,2,3 \text {, }
$$

and $c_{i j k l}^{E}, \theta_{k i j}, s_{j k}^{s}$ are the components of stiffness tensors, plezoelectric constants and dielectric permeability, respectively.

In such a way the roots of eq. ( 4 ) are resonance frequency of $A, B-$ and C-modes, corresponding to longitudinal, quick shear and slow shear BAw, propagating in the direction of the normal $n$ to the plate. For calculation of the 1st-and the 2nd-order temperature coefficients of resonance frequency, temperature constants of crystal have been used and the roots of eq. (4) have been found at several different temperatures. Temperature coefficients of frequency of the $k$ th order $(k=1,2)$ have been calculated as. the 2 nd order polynomial coefficients $f=f(T)$. Calculations haye been made by using a computer. The crystal properties measured data are published in $[2,4]$.

BAw propagation direction was specified by means of two angles $\gamma$ and $\beta$ (figure 1) for the plate of $x y b 1 / \gamma / \beta-c u t$.

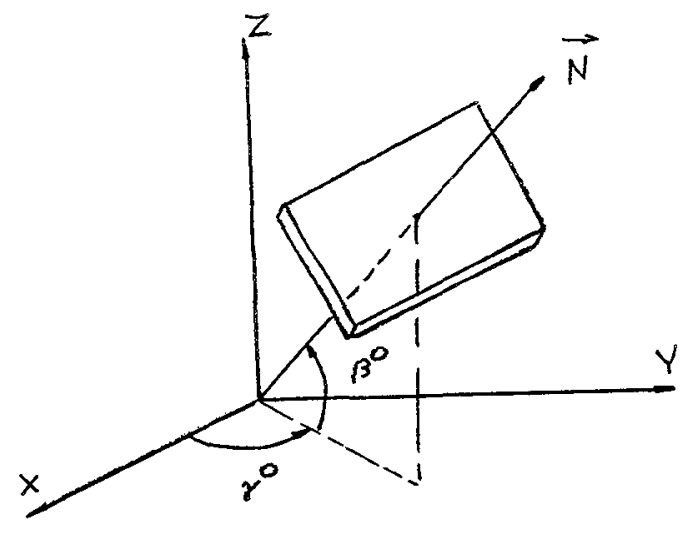

Figure 1. BAW propagation direction for the plate of $x y b l / \gamma / \beta-c u t$. 


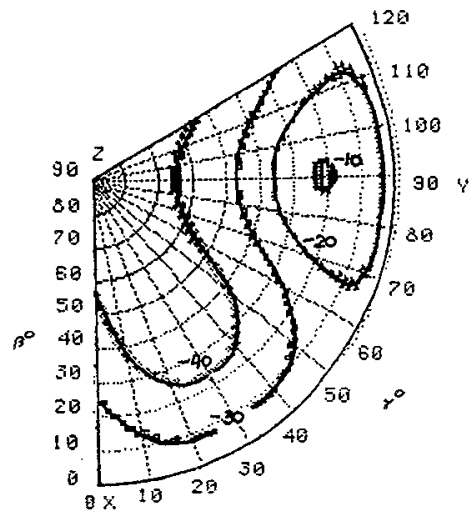

Mode A
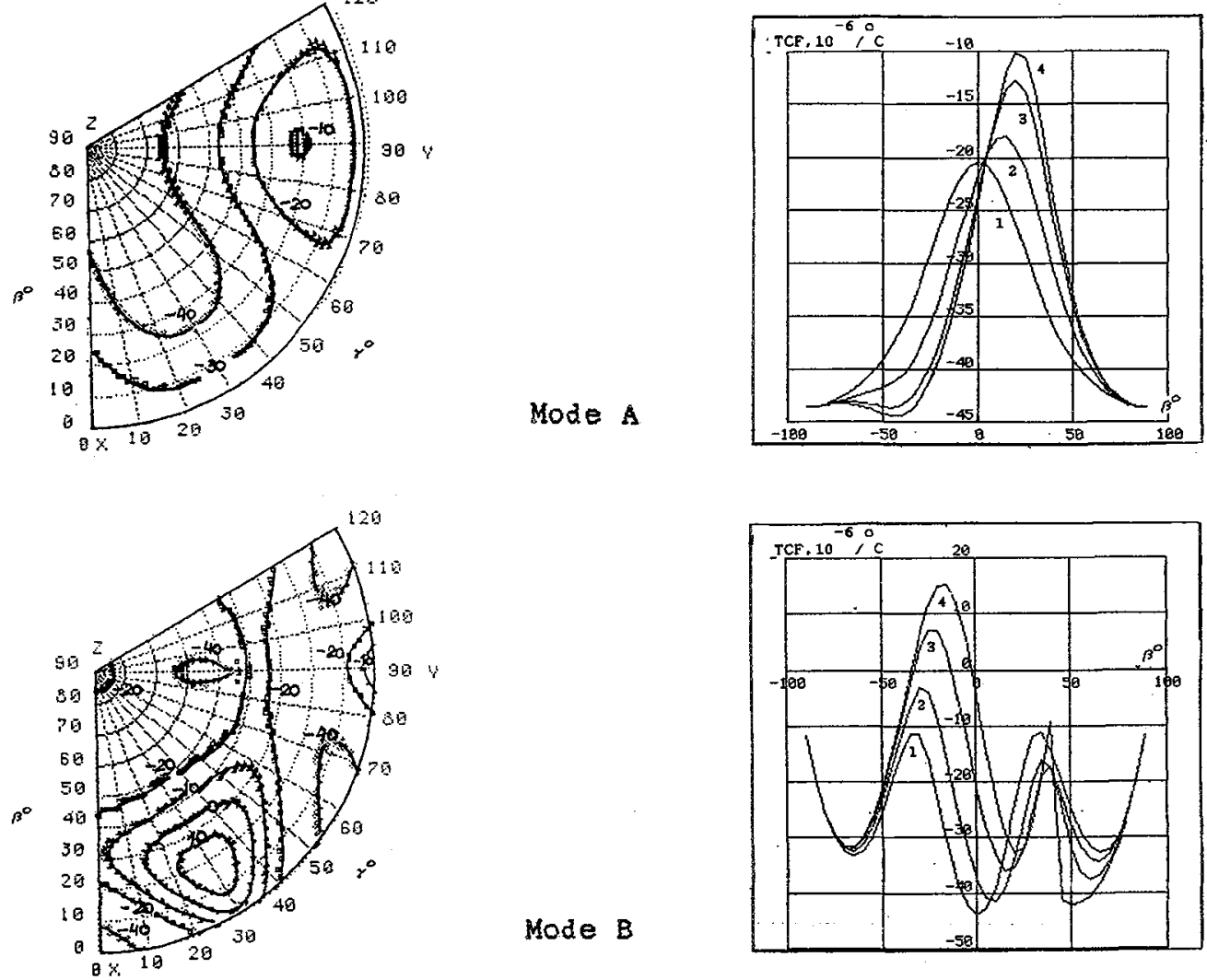

Mode B
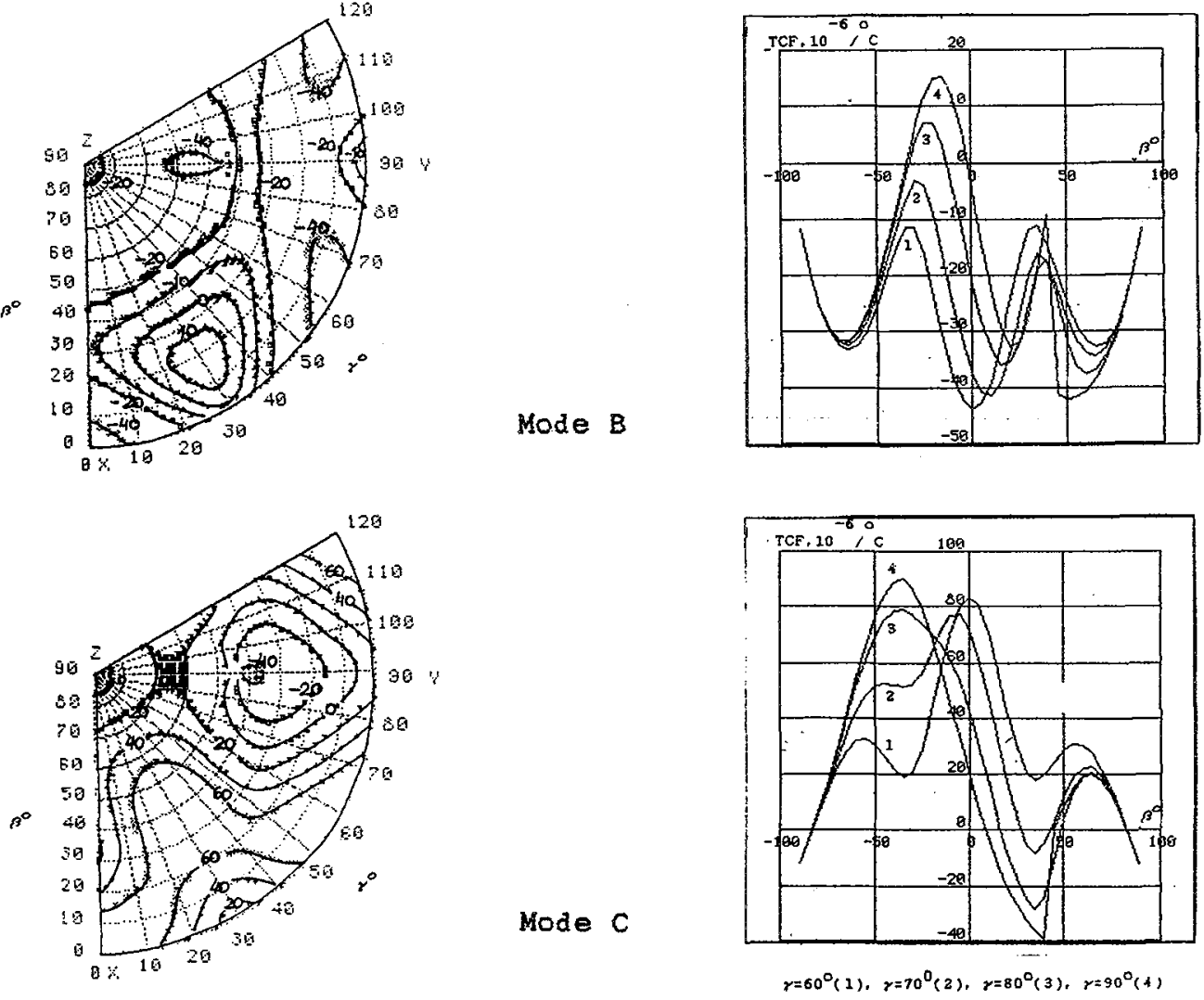

Figure 2. Frequency-temperature coefficient (TCF) of $A, B$ and $C$ modes of langasite crystal. xybl $/ \gamma / \beta$-cuts.

Mode C

Figure 3.Frequency-temperaturs coefficient (TCF) of $A, B$ and $C$ modes of langasite cryetal, yxi/ß-cuts. 

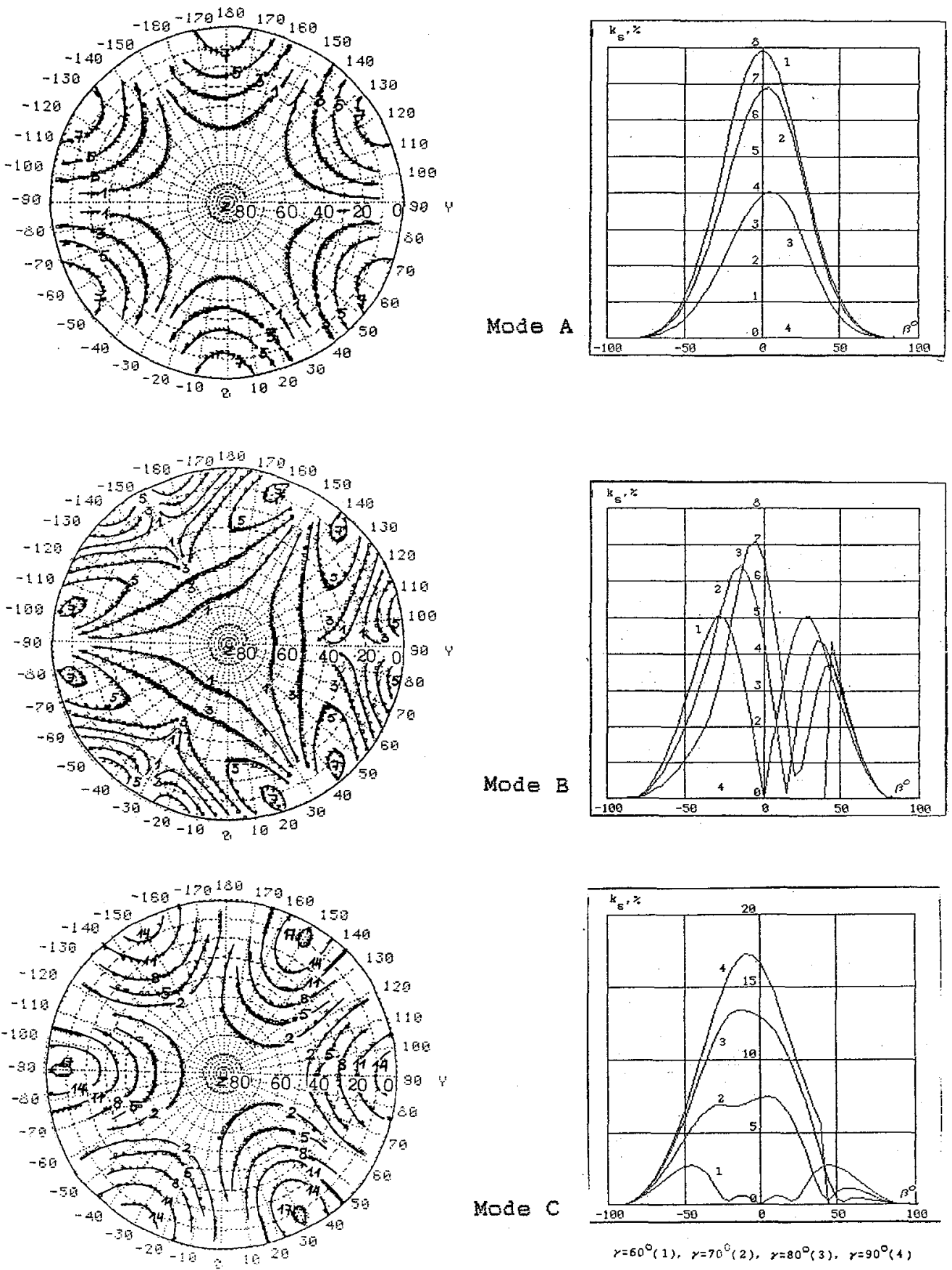

Figure 4. Electromechanical coupling coefficients ( $k_{s}$ ) $A, B$ and $C$-modes of 1 angasite crystal. $x y b l / z / \beta$-cuts.

Figure 3. Electromechanical coupling coefficients $\left(k_{s}\right)$ of $A, B$ and $C$-modes of $l$ angasite crystal, $y \times 1 / \beta$ cuts. 

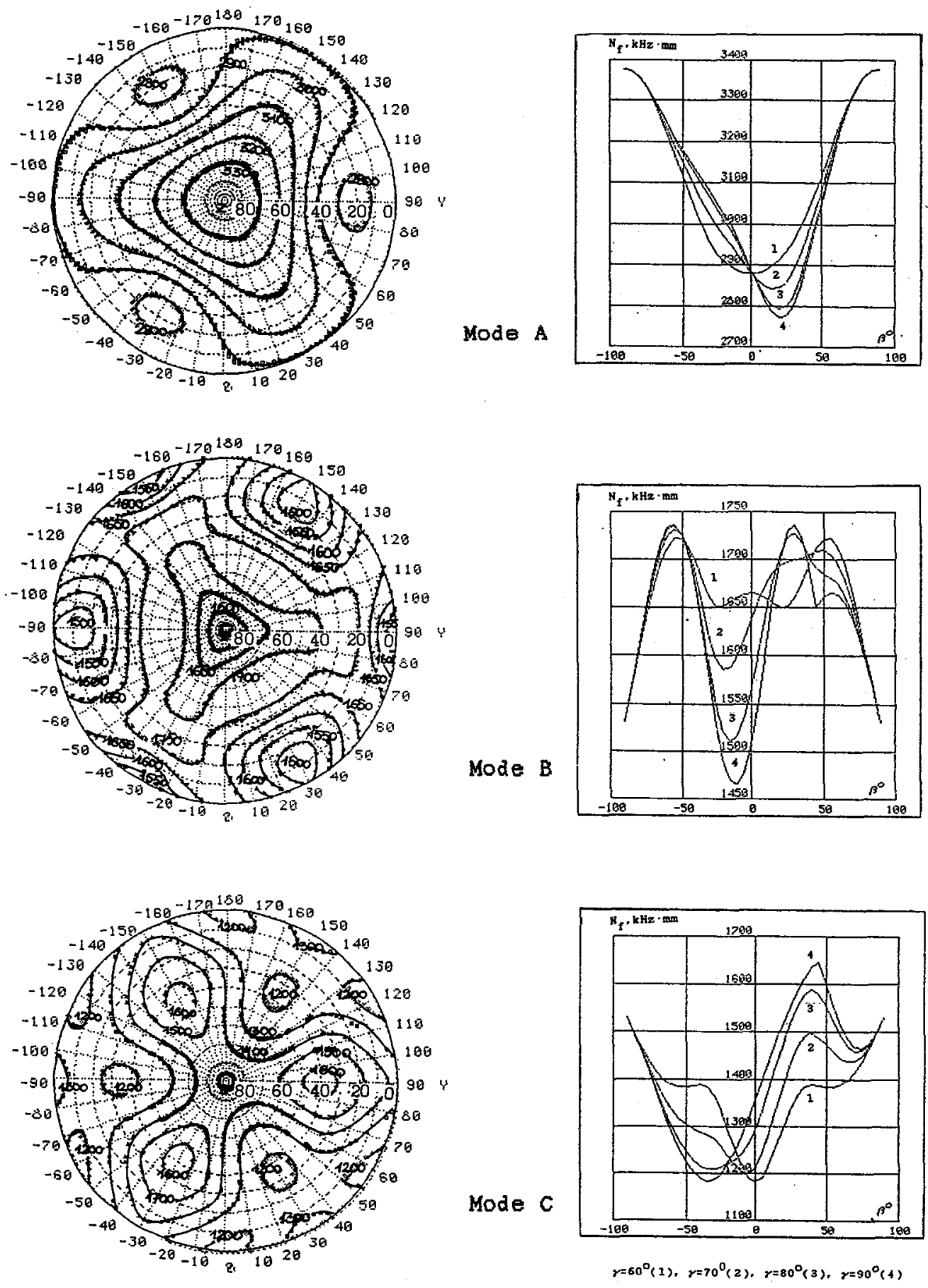

Figure 6. Frequency coefficient of $A, B$ and $C$-mode of langasite crystal, xybl/y/ß-cats.

Figure 7.Frequency coefficient of A,B and C-mode of langasite crystal, yxl/p-cuts. 
Based on the calculation results, it was found that the A-mode of thickness vibrations of langasite plates, analogous to quartz and berlinite, does not have temperature compensated cuts and its temperature coefficient of frequency (TCF) varies from $-40 \cdot 10^{-6}$ to $-10 \cdot 10^{-6},{ }^{\circ} \mathrm{C}$ (figure 2,3 ).

The electromechanical coupling coeficient for the A-mode is not over $8 \%$ and it takes the highest value in the direction of the second order axis. Over the angle range $\beta$ from $50^{\circ}$ to $90^{\circ}$ (cone around the Z-axis) the electromechantcal coupling coefficient is less that $1 \%$ (figure 4,5 ).

The frequency coefficient decreases nearly monotonously from 3380 to $2800 \mathrm{kHz} \mathrm{mm}$ in the direction from the $\mathrm{Z}$-axis towards the $\mathrm{KY}$ -plane (figure 6,7 ).

Therefore the A mode can find a limited application in langasite resonators because the orientation with zero TCF is absent for it.

The TCF of B-mode varies from $-45 \cdot 10^{-6},{ }^{\circ} \mathrm{C}$ to $15 \cdot 10^{-6},{ }^{\circ} \mathrm{C}$. Over the angle range $\gamma$ from $15^{\circ}$ to $45^{\circ}$ and $\beta$ from $0^{\circ}$ to $+35^{\circ} \mathrm{TCF}$ of $B$-mode 15 positive and at the boundary of this region it is equal to zero (figure 2,3).

For these cuts with zero TCF the coupling coefficient varies from $0 \%\left(\gamma=30^{\circ}\right)$ to $7 \%\left(\beta=15^{\circ}, \gamma=45^{\circ}\right)$,

The electromechanical coupling coefficient of B-mode has minima over the angle range $\beta$ from $0^{\circ}$ to $30^{\circ}\left(\gamma\right.$ from $60^{\circ}$ to $\left.120^{\circ}\right)$ and away. from these angles it takes higher value (figure 4,5 ).

The frequency coefficient of B-mode increases from $1500 \mathrm{kHz} \cdot \mathrm{mm}$ to $1700 \mathrm{kHz} \mathrm{mm}$ (figure 6,7 ). The greatest value the frequency constant $N_{f}$ takes over the angle range $\beta$ from $20^{\circ}$ to $40^{\circ}\left(\gamma=90^{\circ}\right)$ and $\beta$ from $40^{\circ}$ to $70^{\circ}\left(\gamma=30^{\circ}\right)$.

Thus, the $B$-mode in langasite has piezoelectrically active zones with TCF equal to zero ( with $k_{s}>0$ ) and can be perspective for resonator application.

The TCF of the C-mode (figure 2,3) varies from $-40 \cdot 10^{-6},{ }^{\circ} \mathrm{C}$ to $100 \cdot 10^{-6} /{ }^{\circ} \mathrm{C}$. This mode is the most interesting one from the point of view of completness of temperature - and piezoelectric properties. At the graph of lines of the TCF level there are two regions where it becomes equal to zero. The electromechanical coupling coefficient of TCF with zero cuts, lying in the region $\beta \approx 80 \div 90^{\circ}$ does not exceed $1 \%$

The region located oyer the angle range $\beta \sim 5^{\circ} \div 50^{\circ}$ and $\gamma \sim 65^{\circ} \div 90^{\circ}$ 
is of greater interest for resonator applications. At the boundary of this angle range the zero TCF is "supplemented" by the electromechanical coupling coefficient which is relatively large for this material. For such cuts with the direction of normal near to that of the $Y$-axis,the electromechanical coupling coefficient ranges from $12 \%$ to $15 \%$ (figure 4,5 ).

The frequency coefficient for the C-mode varies from 1200 to $1600 \mathrm{kHz} \cdot \mathrm{mm}$ for the above-mentioned directions (figure 6,7). Figure 8 represents more detailed dependencies of $\mathrm{N}_{\mathrm{f}}, \mathrm{k}_{\mathrm{g}}$ and $\mathrm{TCF}$ for a single-rotated $Y$-cut of langasite, because just the cuts of $y \times 1 / \beta$ type of this crystal have been used for designing first samples of temperature compensated resonators, operating in thichness shear mode. Analogous dependencies for quartz and berlinite are given. The designed TCF curve of langasite (figure 8,9) passes through zero at $\beta \approx 5^{\circ}$. Certain difference in designed and experimental values of temperature compensated cuts can be explained by the difference in properties of crystals from which resonators have been fabricated and of those crystals which have been used for acoustoelectrical characteristics measurement.

In such a way the condition of minimum TCF and maximum $k_{s}$ satisfy single-rotated $x y 1 / \beta$-cuts, where $\beta$ takes the value of the angle range from $0^{\circ}-5^{\circ}$. The frequency coefficient $N_{f}$ for these cuts is equal to $1360-1400 \mathrm{kHz} \cdot \mathrm{mm}$.

TCF and $k_{5}$ analysis of langasite for $A, B$, and $C$-modes has shown the existence of large areas with zero lst-order TCF and high $k_{s}$. therefore further investigations of langasite as a promising material for BAW resonators are of great interest.

\section{Experimental}

4.1. Theoretical estimation checking

Experimental checking of theoretical TCF, $\mathrm{N}_{f}$ and $\mathrm{k}_{\mathrm{E}}$ estimation have been made by using resonators of xyl/B-cut for different $\beta$-angles. The measurement data are shown in figure 9 and coincide safisfactorily with the theoretical results.

4.2. Experimental langasite resonators operating in thickness sheer mode $C$.

For resonators with crystal elements of $\mathrm{y \times 1} / 0^{\circ}$ - cut the temperature of FTC inflection point correspons to $30-35^{\circ}$, and the 

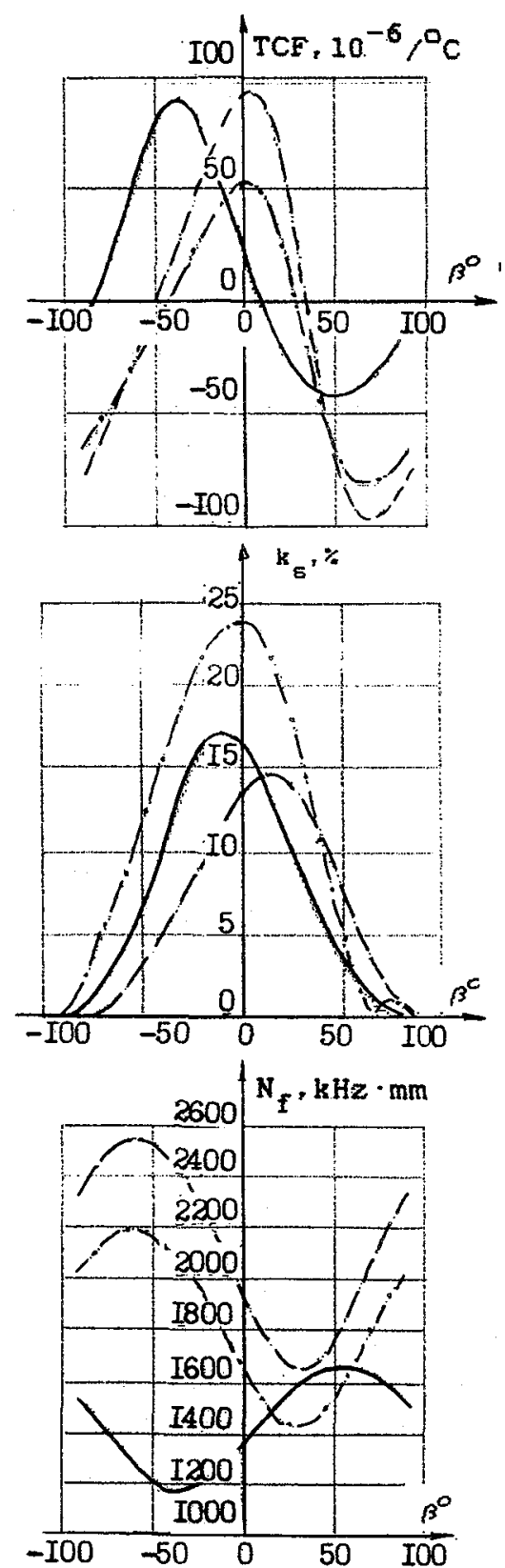

Figure 8. Dependencies of

frequency coefficient (a), of electromechanical coupling

factor(b.) and temperature coefficient of frequency(c) on the rotation angle of $Y-$ cut for: -langasite.

- quartz, -. berlinite.

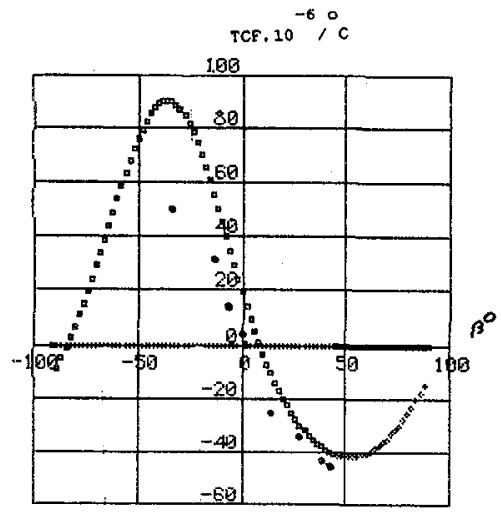

$$
\mathrm{s}, \%
$$
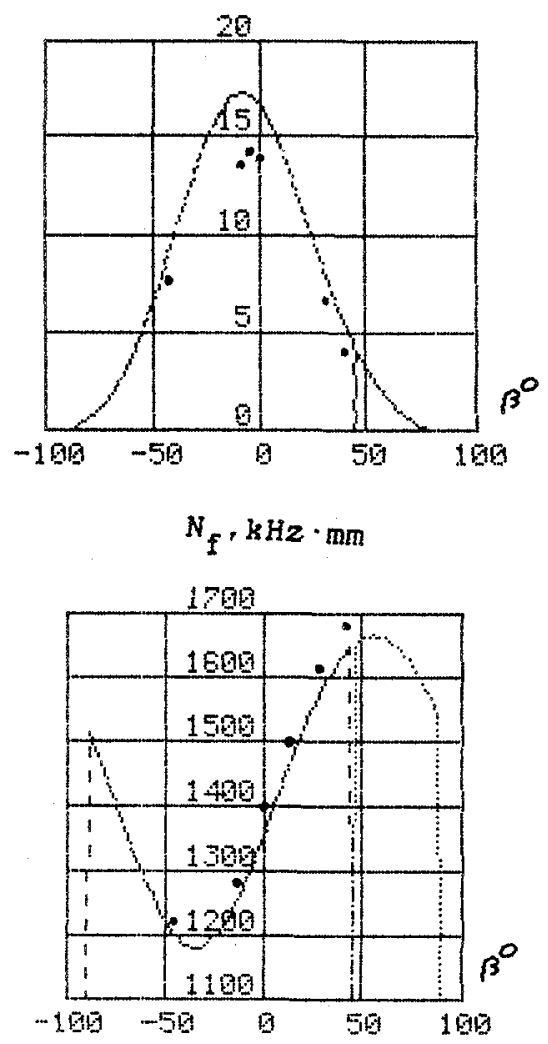

Figure 9.Theoretical and experimental curves FTC, $N_{f}$ and $k_{E}$ of langasite crystal: a-theoretical data, - experimental data. 
frequency coefficient is equal to $1380 \mathrm{kHz} \cdot \mathrm{mm}$. With enlarging angle of cut the inflection point of FTC shifts towards negative temperatures and the frequency coefficient becomes greater, the resonanse spacing becomes narrower. The main resonator characteristice are shown in table 15 .

Table 15

Paramoters of langasite resonators operating in thickness-shear mode

\begin{tabular}{|c|c|c|c|c|c|c|c|}
\hline $\begin{array}{c}\text { Frequency } \\
\mathrm{MHz}\end{array}$ & $Q$ & $\begin{array}{r}R_{1} \\
\text { ohm }\end{array}$ & $\begin{array}{l}L_{1} \\
H\end{array}$ & $c_{1}$ & $\begin{array}{l}c_{0} \\
p F\end{array}$ & $\begin{array}{l}\text { Resonance } \\
\text { spacing } \\
\text { value, }\end{array}$ & $\begin{array}{l}\text { Maximum relative } \\
\text { Irequency devia- } \\
\text { tion, } 10^{-6} \\
\left(-60 \div 85^{\circ} \mathrm{C}\right)\end{array}$ \\
\hline 10.7 & 15000 & 6 & 0.0052 & 0.038 & 3.19 & 0.7 & $-(300-400)$ \\
\hline 21.4 & 12000 & 30 & 0.0045 & 0.012 & 1.31 & 0.6 & $-(300-400)$ \\
\hline
\end{tabular}

Langasite resonators operating at 8-10 MHz have been also manufactured for VCxo application.

It is expected that in the osciliator circuit the pulling range and the pulling sensitivity characteristics can ce improved by $2-3$ times.

4.3. Langasite resonators operating in longitudinal mode.

Resonators $350 \mathrm{kHz}$ of xys/a -cut, where $a^{\circ}$ varies from $0^{\circ}$ to $-4^{\circ}$, in metal enclosure $V=1.5 \mathrm{~cm}^{3}\left(C_{0} a 0.3 \mathrm{pF}\right)$ and resonators at $128 \mathrm{kHz}$ in glass enclosure $y=1.5 \mathrm{~cm}^{3}\left(C_{0}-1.7 \mathrm{pF}\right)$, for $w / 1 \leq 0.17$ and $t=0.45 \mathrm{~mm}$ thickness (1) and $t=0.65 \mathrm{~mm}$ (2) have the parameters presented in table 16 .

Table 16

Parameters of langasite resonators operating in longitudinal mode

\begin{tabular}{|c|c|c|c|c|c|c|c|c|}
\hline $\begin{array}{l}\text { Frequency } \\
\qquad \mathrm{kHz}\end{array}$ & $Q$ & $\begin{array}{r}R_{1} \\
\text { ohm }\end{array}$ & $\begin{array}{l}\mathrm{L}_{1} \\
\mathrm{H}\end{array}$ & $c_{1}$ & & $\begin{array}{c}\text { Resonance } \\
\text { spacing } \\
\%\end{array}$ & $\begin{array}{c}\mathrm{N}_{\mathrm{f}} \\
\mathrm{kHz} \cdot \mathrm{mm}\end{array}$ & $\begin{array}{l}\text { Maximum relati- } \\
\text { ve frequency } \\
\text { deviation } 0^{-6} 10^{-6} \\
(-60 \div 85 \mathrm{c})\end{array}$ \\
\hline $128(1)$ & 50000 & 100 & 5.9 & 0.27 & 17.1 & 0.8 & 2300 & -450 \\
\hline $128(2)$ & 50000 & 70 & 3.7 & 0.41 & 26.2 & 0.8 & $\sim 2300$ & -350 \\
\hline $350(1)$ & 25000 & 400 & 6.1 & 0.07 & 3.9 & 0.8 & $\sim 2300$ & -400 \\
\hline
\end{tabular}

Langasite resonator dependence on piezoelectric element design is analogous to that of quartz resonators. The steepness coefficient of 
frequency-temperature characteristic for the left branch is equal to $-5 \cdot 10^{-8},{ }^{\circ} \mathrm{C}^{2}$ and for the right branch it is equal to $-7 \cdot 10^{-8} /{ }^{\circ} \mathrm{c}^{2}(3.5$ and $4.5 \cdot 10^{-8},{ }^{\circ} \mathrm{c}^{2}$ for quartz resonators, respectively).

The extremum point of irequency - temperature characteristic (FTC) shifts towards positive temperatures with the increase of width (w) to length (1) ratio, thickness ( $t$ ) and rotation angle a of elements. The frequency coefficient of resonators $\mathrm{N}_{f} \approx 2300 \mathrm{kHz} \cdot \mathrm{mm}$ decreases slowly with the $w / 1$ and $\alpha$ increase. Resonator inductance decreases $w i t h w / 1$ and increase, with the quality factor and resonance spacing values increase being increased to $0.8-1 \%$. The main difference of these resonators from the quartz crystal ones is in their lower by approximately 1.5 times and by twice lower inductance and resistance, 4-5 times greater resonance spacing.

The steepness of resonator frequency - temperature characteristic curve decreases with the increase of piezoelectric element thickness. FTC extremum shifts towards postive temperatures with the increase of $w / 1, S$ and $a^{\circ}$. Resonator frequency coefficient $N_{f} \approx 2300 \mathrm{kHz} \cdot \mathrm{mm}$ slowly increases with $w / 1$ and $\alpha^{\circ}$ decrease.

The TCF and $\mathrm{k}_{\mathrm{g}}$ analysis of langasite for $\mathrm{A}, \mathrm{B}$, and $C$-modes has shown the existence of large areas with zero lst-order TCF and high $k_{5}$, therefore further investigations of langasite as a promising material for BAW resonators are of great interest.

For more exact LGS-resonator perspectivity evaluation for application in piezoelectronic engineering application further experimental and theoretical investigations are necessary aimed at obtaining higher frequency stability, higher $Q$ and improvement of electrical characteristics of the resonators.

\section{Introduction}

[1]. Kaminskii A.A., Mill B.Y., Khodzhabanyan G.G. et.a1.. J.Phys.stat.sol. (a) 80 (1983) 387 .

[2]. Kaninshii A.A.,Silvestrova I.M.,Sarkisov S.E., Denisenko G.A., J.Phys.stat.sol. (a) 80 (1983) 607.

[3]. Kaninski i A.A., Belokoneva E.L., Mil1 B.V., J.Phys.stat.sol. 86 (1984) 345.

[4].Silyestrova I.M.,Pissareysky Yu, V., Senychenkov P.A., Krupny A. I., J.Phys.stat.sol.(Russia), 28 N9 (1986) 2875.

[5]. Ilyaev A.B., Umarov B.5., Shabanova L.A. Dubovik M.F., Phys.stat.so1. (a) 98 (1986) K109. 
[6]. Grouzineniko Y.B., Bezdelk in V.V., "Piezoelectric resonators based on single crystals of strong piezoelectrics", Proc. of the 45 Ann. Symp.on Freq. Contr, Los Angeles, California 29-31 May 1991, p. 212 .

[7]. Grouzinenko V.b., Bezdelkin Y.V., "Piezoelectric resonatore from $\mathrm{La}_{3} \mathrm{Ga}_{5} \mathrm{SiO}_{14}$ - single crystals", Proc.of the 46 Ann.Symp.on Freq. Contr., Hershey, Pensylvania 27-29 May 1992 p.707.

[3].Tiersten H.F., J.Acoust.Soc.Amer. 35 (1963) 53.

[9]. Yamada T,Ni iseki N., Fros. IEEE 58 (1970) 941 .

[10]. Silvestrova I.M., Bezdelkin V.V., Senyushenkov P.A.,

Pissarevsky Yu.V., "Present stage of $\mathrm{La}_{3} \mathrm{Ga}_{5} \mathrm{SiO}_{14}$ - research", Pros. of the 47 Ann. Symp. on Freq. Contr., Salt Lake City, Utah 2-4 June $1993, \mathrm{P} .348$.

[11].Silyestrova I.M. Pissarevsky Yu.V., Bezdelkin V.Y., Senyushenkov P.A. "New piezoelectric materials", Proc. of the 47 Ann. Symp.on Freq. Contr., Salt Lake City, Utah 2-4 June 1993,p.351. 